\title{
Natural mineral-organic associations studied by XRF and P-edge XANES
}

J. THIEME ${ }^{1}$, K. EUSTERHUES ${ }^{2}$, L. LUEHL ${ }^{3}$, A. HAIDL ${ }^{4}$, T. WILHEIN ${ }^{4}$, B. KANNGIESSER ${ }^{3}$, K. TOTSCHE ${ }^{2}$.

${ }^{1}$ NSLS II, Brookhaven National Laboratory, USA

(correspondence: jthieme@bnl.gov),

${ }^{2}$ Inst. of Geosciences, Jena University, Germany

${ }^{3}$ Inst. for Optics and Atomic Physics, TU Berlin, Germany

${ }^{4}$ Inst. for X-Optics, Univ. Appl. Sci. Koblenz, Germany

The association of organic molecules with mineral surfaces is a major mechanism to stabilize soil organic matter against biodegradation. Strong inner-sphere iron phosphate complexes are of particular importance for the attachment of microorganisms to iron oxides, either by exudation of extracellular polymeric substances or by interactions of cell membrane molecules with the mineral surface. These P-O-Fe bonds are not easily detected because of the difficulty to detect individual bonding mechanisms in a complex matrix of organic matter and minerals in soils. To investigate for these bonds, $\mathrm{P}$ K-edge XANES spectroscopy measurements with a spatial resolution $<100 \mathrm{~nm}$ on secondary minerals from soils and sediments were performed to determine whether $\mathrm{P}-\mathrm{O}-\mathrm{Fe}$ bonds exist on pedogenic iron oxides and whether $\mathrm{C}-\mathrm{O}-\mathrm{Fe}$ bonds from carboxylic groups are overrated with respect to mineral binding. XRF maps allow to differentiate between clay minerals and $\mathrm{Fe}$ oxides and help to locate $\mathrm{C}$-rich and P-rich regions on these minerals. As the spatial distribution of $\mathrm{P}$ in soils is heterogeneous (Fig. 1), element specific techniques with a high spatial resolution and a high energy resolution are the ideal tools to resolve such research questions. XRF maps and XANES image stacks at the K-absorption edges of carbon and phosphorus have been measured on sediments using the AnImaX STXM-endstation set up at beamline P04 of PETRAIII at DESY. Results will be presented.

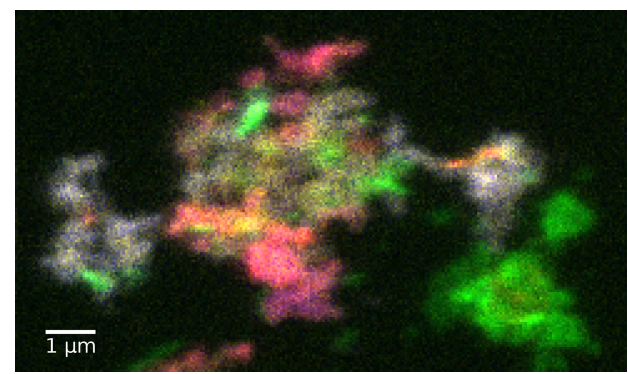

Fig. 1: False color overlay of XRF maps showing Fe oxides and clay minerals from a creek sediment. Step size: $50 \mathrm{~nm}$. The color scale shows the heterogeneous distribution of $\mathrm{P}$ (red), S (yellow), Fe (blue), and $\mathrm{Al}$ (green). 